\title{
Seroprevalence of mumps before inclusion of mumps vaccination in the Iranian Expanded Programme on Immunization
}

M. Avijgan, ${ }^{1,2}$ R. Habibian ${ }^{2}$ and S. Kheiri ${ }^{3}$

$$
\text { معدَّل الانتشار المصلي للنكاف قبل إدراج التلقيح ضده في البرنامج الإيراني الموسَّع للتمنيع }
$$

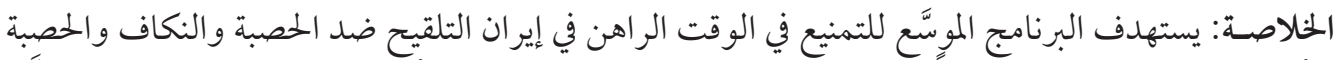

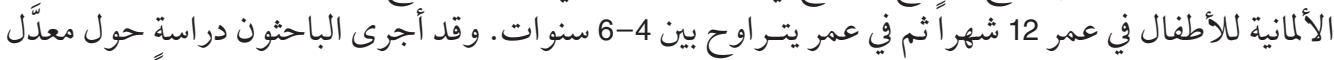

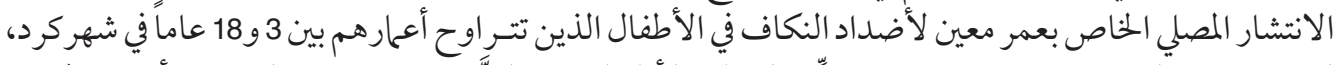

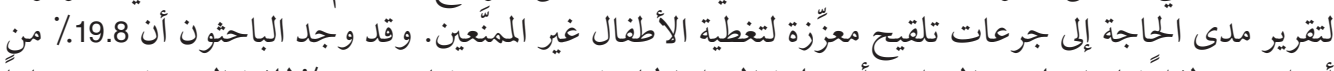

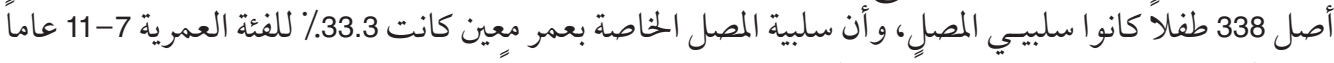

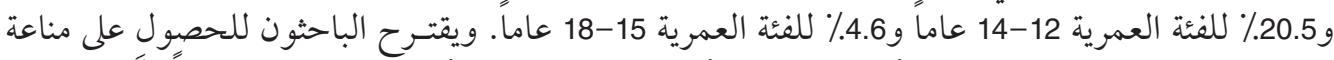

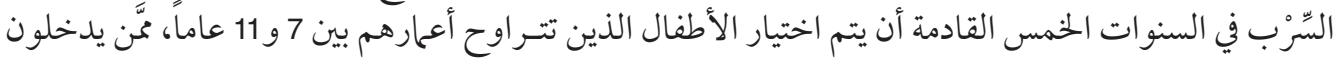

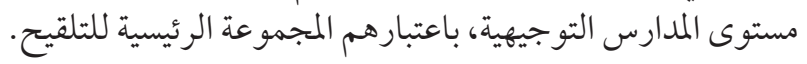

ABSTRACT The current target groups for measles, mumps and rubella vaccination in the Islamic Republic of Iran are children at 12 months and 4-6 years. A study of the age-specific seroprevalence of antibodies against mumps in children aged 3-18 years in Shahrekord aimed to establish the need for booster vaccinations to cover non-immune children. Of 338 children, $19.8 \%$ were seronegative. Age-specific seronegativity was $33.3 \%, 20.5 \%$ and $4.6 \%$ in age groups $7-11,12-14$ and $15-18$ years respectively. To obtain herd immunity, we suggest that for the next 5 years children aged $7-11$ years entering guidance school are selected as the main group for vaccination.

Séroprévalence des oreillons avant l'intégration de la vaccination anti-ourlienne dans le programme élargi de vaccination iranien

RÉSUMÉ À l'heure actuelle, les groupes visés par la vaccination contre la rougeole, les oreillons et la rubéole en République islamique d'Iran sont les enfants âgés de 12 mois et ceux âgés de 4 à 6 ans. Une étude de la séroprévalence par âge des oreillons chez les enfants âgés de 3 à 18 ans a été menée à Shahrekord, dans le but de déterminer s'il y avait lieu de procéder à des vaccinations de rappel afin de protéger les enfants non immunisés. Sur 338 enfants, 19,8\% étaient séronégatifs. La séronégativité selon le critère de l'âge était respectivement de $33,3 \%, 20,5 \%$ et $4,6 \%$ dans les groupes de sujets âgés de 7 à 11 ans, de 12 à 14 ans et de 15 à 18 ans. Pour obtenir une immunité collective, nous suggérons que pendant les 5 prochaines années, le principal groupe vacciné soit les enfants âgés de 7 à 11 ans, avant leur entrée dans le second degré.

${ }^{1}$ Department of Infectious and Tropical Diseases and Iranian Traditional Medicine Research Centre, Isfahan University of Medical Sciences, Isfahan, Islamic Republic of Iran (Correspondence to M. Avijgan: avijgan@ yahoo.com).

${ }^{2}$ Department of Infectious and Tropical Diseases, Faculty of Medicine; ${ }^{3}$ Department of Biostatistics, Faculty of Health, Shahrekord University of Medical Sciences, Shahrekord, Islamic Republic of Iran.

Received: 30/04/06; accepted: 24/09/06

المجلة الصحية لشرق المتوسط، منظمة الصحة العالمية، المجلد الخامس عشر، العدد Y، 9 +. 


\section{Introduction}

The selection of a target group for the Expanded Programme on Immunization (EPI) is important [1]. The proportion of individuals in a population with doubtful protection (unvaccinated, nonresponders and low responders after primary vaccination) affects the chances of immunity reaching the $95 \%$ threshold that is necessary for herd immunity [2]. The population with doubtful protection must be a target group for vaccination and this can only be established by seroprevalence studies. A serological prevalence survey carried out in Izmir, Turkey to determine the antibody status of a population aged 1-29 years against mumps infections reported that $20.1 \%$ were seronegative [3]. Previous studies carried out in Shiraz and Tehran in the Islamic Republic of Iran reported that $34.2 \%$ of the population of Shiraz and $82.3 \%$ of 5-year-olds and $29.4 \%$ of 10-year-olds in Tehran were seronegative $[3,4]$. On the basis of these results it can be seen there is a wide range of seronegativity among various age group which could affect the selection of a target group.

After March 2004, vaccination against mumps, measles and rubella (MMR) was included in the Iranian EPI. The target groups for MMR vaccination are children at 12 months and 4-6 years. There have been a limited number of studies determining the status of immunity against mumps in the Islamic Republic of Iran $[4,5]$, and we believe that there is insufficient evidence to justify the selection of these target groups.

The main goal of this study was to establish the age-specific antibody seroprevalence against mumps in Iranian children aged 3-18 years. The other aims were to obtain a baseline level of seroprevalence for repeated surveillance of current vaccination in the years following vaccination (at least in the region of the study) and also to establish the need for booster vaccinations to cover nonimmune children. The seronegative group could be helpful to evaluate the efficacy of mumps vaccine (manufactured in the Islamic Republic of Iran) in future studies.

\section{Methods}

This was a cross-sectional study conducted in 2004 in Shahrekord, the capital city of Chahar-Mahal and Bakhtiari province in the south-west of the Islamic Republic of Iran.

\section{Sample}

The target group was children 3-18 years old. Based on limited previous studies [4,5], the estimated seronegativity of mumps among this population was $20 \%$, and from this a sample size of 338 children was determined. In the Islamic Republic of Iran, about $100 \%$ of children aged $7-18$ years old go to school and about $95 \%$ of those aged 3-6 years go to day care centres.

We obtained the sampling frame from a local educational organization which included 158 schools (primary schools, guidance schools and high schools) and 100 day care centres. Sampling was conducted by a 3 -stage sampling method. In the first stage the total population of students was stratified according to day care centres, primary schools, guidance schools and high schools. Due to the lack of detailed previous prevalence studies on mumps, we used the probability proportional to size sampling technique, which means that samples were selected according to the proportion of children in each stratum. Each stratum included several clusters (educational units), and in the 2nd stage, clusters were randomly selected. We selected 7 schools from the primary schools, guidance schools and high schools ( 3 units for girls and 4 units for boys, except for guidance schools where 2 units 
were selected for boys). In the last stage, in each cluster, samples were randomly selected from day care centres $(n=25,9.2 \%)$, primary schools $(n=103,30.5 \%)$, guidance schools $(n=151,44.7 \%)$ and high schools $(n=59,17.5 \%)$. There were 191 boys and 147 girls, male to female ratio 1.3:1.

\section{Data collection}

Data collection was based on an interview questionnaire and serology testing.

The parents of selected children were given a formal invitation to attend the school where their consent to participation was obtained. We did not encounter any refusals and, with the cooperation of the manager of schools, all selected children participated in the study. The parents were interviewed by our coinvestigator (a general practitioner) to collect data such as age, sex, history of previous exposure to mumps cases, history of previous mumps involvement and vaccination against mumps (these last 3 items were recorded as self-reported). Mumps was defined as a swelling of the parotid gland which lasted for at least 5-7 days accompanied by fever and difficulty eating.

After filling in the questionnaire, $10 \mathrm{~cm}^{3}$ of venous blood was taken from each child and centrifuged sera were frozen at $-20^{\circ} \mathrm{C}$. At the end of blood sampling, all tests were carried out simultaneously. IgG was measured using mumps IgG (ELISA) kits and instruments from Trinity Biotech Capita (Jamestown, United States of America). The quality control was done simultaneously with the measurement of samples. Based on the recommendation of the kit, negative and positive control numbers and the mean values were in an acceptable range. Based on the kit definition, the results were calculated as antigen-antibody ratios, and recorded as positive or negative.

Ethical approval for the study was obtained from the ethical committee of the University, and referred to the local educational organization for approval.

\section{Statistical analysis}

Statistical analysis was performed using the chi-square test and SPSS, version 11.5. $P$-value $<0.05$ was considered statistically significant.

\section{Results}

Overall seroprevalence was $80.2 \%$ and therefore $19.8 \%$ of children tested were sensitive to mumps infection (Table 1).

The sex-specific seroprevalence was $77.1 \%$ for females and $82.5 \%$ for males. Age-specific seroprevalence rose from $66.7 \%$ for age group 7-11 years (primary school) to $79.5 \%$ for age group $12-14$ years (guidance school) for $95.4 \%$ at age group

$\begin{aligned} & \text { Table 1 Age-specific seroprevalence of mumps IgG antibodies by sex and } \\
& \text { seropositivity }\end{aligned}$
\begin{tabular}{lrrrrrr}
\hline $\begin{array}{l}\text { Age group } \\
\text { (years) }\end{array}$ & \multicolumn{7}{c}{ Positive } & \multicolumn{2}{c}{$\begin{array}{l}\text { Serological reaction } \\
\text { Negative }\end{array}$} & \multicolumn{1}{c}{ Total } \\
& No. & $\%$ & No. & $\%$ & No. & $\%$ \\
\hline $3-6$ & 25 & 100.0 & 0 & 0.0 & 25 & 7.4 \\
$7-11$ & 68 & 66.7 & 34 & 33.3 & 102 & 30.1 \\
$12-14$ & 116 & 79.2 & 30 & 20.8 & 146 & 43.2 \\
$15-18$ & 62 & 95.4 & 3 & 4.6 & 65 & 19.2 \\
Total & 271 & 80.2 & 67 & 19.8 & 338 & 100.0 \\
\hline$P<0.05$. & & & & & &
\end{tabular}

المجلة الصحية لشرق المتوسط، منظمة الصحة العالمية، المجلد الخامس عشر، العدد Y، 9 ·. 
15-18 years (high school) (Table 1). The age group 3-6 years was 100\% immune (Table 1). Using the chi-squared test, there was a significant difference between age and seroprevalence $(P<0.05)$.

There was a past history of mumps reported in 259/338 children (76.6\%). Serology confirmed this in $76.4 \%$ of these cases. There was no reported history of mumps in 79 children (23.4\%). Nevertheless serology was positive in $92.4 \%$ of these cases (Table 2). Using the chi-squared test, there was a significant difference in the agreement between serology and reported past history of mumps $(P<0.05)$

There was reported past history of vaccination against mumps in 49 children $(14.5 \%)$. The seroprevalence for mumps was significantly higher for vaccinated $(42 / 49 ; 85.7 \%)$ than unvaccinated children $(229 / 289 ; 79.2 \%)$ (Table 2$)$. The chi-squared test showed a significant difference in the rate of agreement between serology and reported history of vaccination $(P<0.05)$.

There was reported past history of close contact with a case of mumps in $82 / 338$ children $(24.3 \%)$. Serology agreed with the past history of close contact in $86.6 \%$ of such cases for mumps. There was no such history in 256 children (75.7\%). Serology was positive in $78.1 \%$ of such cases (Table $2)$. The chi-squared test showed no statistically significant difference in the rate of agreement between serology and reported past history of close contact with a mumps case.

\section{Discussion}

Although MMR vaccination has been included in the Iranian EPI since March 2004, it is not clear why the present age groups $(12$ months and 4-6 years old) were selected for

\begin{tabular}{|c|c|c|c|c|c|c|}
\hline \multirow[t]{3}{*}{ Variable } & \multicolumn{6}{|c|}{ Serological reaction } \\
\hline & \multicolumn{2}{|c|}{ Positive } & \multicolumn{2}{|c|}{ Negative } & \multicolumn{2}{|c|}{ Total } \\
\hline & No. & $\%$ & No. & $\%$ & No. & $\%$ \\
\hline \multicolumn{7}{|l|}{$\begin{array}{l}\text { Past history of mumps } \\
\text { involvement }\end{array}$} \\
\hline Positive history of mumps & 198 & 76.4 & 61 & 23.5 & 259 & 76.6 \\
\hline Negative history of mumps & 73 & 92.4 & 6 & $\begin{array}{r}7.6 \\
<0.05\end{array}$ & 79 & 23.4 \\
\hline \multicolumn{7}{|l|}{$\begin{array}{l}\text { Past history of mumps } \\
\text { vaccination }\end{array}$} \\
\hline Vaccinated & 42 & 85.7 & 7 & 14.3 & 49 & 14.5 \\
\hline Unvaccinated & 229 & 79.2 & 60 & $\begin{array}{r}20.8 \\
<0.05\end{array}$ & 289 & 85.5 \\
\hline $\begin{array}{l}\text { Past history of close contact } \\
\text { with mumps case }\end{array}$ & & & & & & \\
\hline Positive history of contact & 71 & 86.6 & 11 & 13.4 & 82 & 24.3 \\
\hline Negative history of contact & 200 & 78.1 & 56 & $\begin{array}{r}21.9 \\
<0.05\end{array}$ & 256 & 75.7 \\
\hline
\end{tabular}


mumps vaccination. One reason may be the convenience of the simultaneous administration of measles and rubella.

The method used in our study was ELISA testing, which was assumed to be suitable, specific and more sensitive than neutralization and complement-fixation [6]. A Dutch study also indicated that indirect ELISA is a reliable method for measuring mumps virus-specific antibodies in populationbased studies [7].

Our study found a seronegativity rate of $19.8 \%$, which is lower than the rates reported in previous Iranian studies $(34.2 \%$ and $29.4 \%$ ) $[4,5]$, but similar to the rate reported in Izmir, Turkey (20.1\%) [3]. However, wide discrepancies can occur: for example, another Turkish study reported a rate of only $10.9 \%[8]$.

The sex-specific rates in our study showed a significant difference in seronegativity between females and males (29.9\% and $17.5 \%$ respectively). In a study in Shiraz, $31.4 \%$ of girls and $35.8 \%$ of boys tested seronegative for mumps antibodies [4]. The rate of seronegativity in another study was also higher in males than females [8]. Reasons for the higher rates of seronegativity in males in Shiraz are unclear, although there may be different levels of outdoor activity (e.g. boys spending more time outdoors than girls) or different levels of family crowding between the provinces.

In our study the age-specific seropositive rate rose rapidly from $66.7 \%$ at age $7-11$ years to $79.2 \%$ at age $12-14$ years and $95.4 \%$ at age $15-18$ years.

A British study revealed that over $80 \%$ of children aged 1-2 years did not have antibodies to mumps and rubella [9]. This is in contrast to our findings that $100 \%$ of children aged 3-6 years had antibodies to mumps. This may be due to the level of public health action concerning communicable diseases. However, the seropositive rate of $100 \%$ in day care centres may be overreported due to local and seasonal outbreaks of mumps.

Among 8th grade students, in a Swiss study, $87 \%$ of the children tested seropositive for mumps-specific antibodies [10], similar to our findings. The prevalence of mumps IgG antibodies in a randomly selected population of children aged 1-17 years determined by ELISA showed that mumps antibodies were acquired at an early age [11]. The peak acquisition rate occurred at age 4-5 years; as in our study. In addition, the study showed that before age 15 years, $90 \%$ of children had antibodies to mumps [11], which is lower than our rate of $95.4 \%$. A prevalence study of 333 students at Jordan University showed most of the students (93.7\%) tested seropositive for mumps antibodies. Mumps occurred in all age groups in both sexes and the rate was higher in children aged 5-14 years than in adults [12]. This is in contrast to our results.

Our review of a number of previous studies carried out to detect the optimal age for vaccination showed conflicting results, suggesting that the findings depend on the age of the studied group $[3,5,8,9,13,14]$. For example, an Iranian study suggested that vaccination at age $1-5$ years is most beneficial because $82.3 \%$ of subjects were seronegative [5]. Another study in India, indicated that, because children are at greatest risk of mumps by age 9 years, this age may be most beneficial for vaccination [13]. In addition a study carried out among infants up to 2 years of age concluded that MMR vaccination at 12 months instead of 15 months could reduce the pool of susceptible subjects in infancy [14]. A study in England on children aged 1-4 years suggested that vaccinating children early in the 2 nd year of life is necessary to eliminate the 3 diseases [9]. A Turkish study in Ankara indicated the routine health supervision visit at age

المجلة الصحية لشرق المتوسط، منظمة الصحة العالمية، المجلد الخامس عشر، العدد ب، 9 +. 
11-12 years was the ideal time to immunize unvaccinated adolescents [8], whereas another study in Izmir suggested that age 1-10 years was the ideal time to immunize unvaccinated children [3].

We found a high non-immune status among children aged 7-14 years. These findings suggest that a large proportion of these children $(20.5 \%-33.3 \%)$ are at risk in our population, and that mumps or MMR vaccination at this age may be most beneficial. We recommend that mumps immunization of these children is important until an EPI for mumps with high coverage can be sustained.

There was a reported past clinical history of mumps in $76.6 \%$ of children, confirmed serologically in $76.4 \%$. This is similar to a previous study which suggests serology agreed with the clinical history of the subject in $82 \%$ of cases for mumps [15]. There was no clinical history of mumps in $23.4 \%$ of children, but serology was positive in $92.4 \%$ of these cases. This significant discrepancy may be due to several reasons, such as parents' poor memory, subclinical presentation of mumps or self-diagnosis and management. Similar to our study, another study showed that the frequency of seronegative subjects who were reported to have had the disease was low $(<8 \%)$ [14].

In one study, the reported rate of past history of mumps vaccination in students without antibodies was $85.0 \%$, and in those with low-titre antibody students was $93.8 \%$ [16]. We found that the past history of mumps vaccination was reported at a rate of $14.5 \%$ and $85.7 \%$ were seropositive.

\section{Limitations of the study}

There have been similar studies conducted in other provinces $[3,4]$ and this is a regional study which cannot be generalized to the rest of the population of schoolchildren in the Islamic Republic of Iran. This kind of study needs to be repeated with a larger, more extended sample size to obtain more reliable results. Another limitation of this study was determining the number of units in each stratum, so that for sampling we were obliged to use the method of probability proportional to size. If we had the prevalence rate for each stratum then it would be possible to compute the samples by stratum and this would result in a more exact sampling procedure.

\section{Conclusions}

The Iranian EPI targets children at 12 months and 4-6 years old for MMR vaccination. However, based on the results of our study, and since a high seronegative rate may shift mumps infection to older ages, we believe mumps immunization of children aged 7-11 years entering guidance school is important and that for the next 5 years they must be selected as the main group for vaccination so that a national mumps vaccination programme with a high coverage can be sustained. The routine health supervision visit at ages 7-14 years is also an ideal time to immunize unvaccinated adolescents. This may increase the immunity to the $95 \%$ level necessary for herd immunity and elimination of the disease. After that time children less than 6 years old may be the only group needing mumps vaccination.

\section{Acknowledgements}

We thank the research council of Shahrekord University of Medical Sciences for their financial support. We are also grateful to Dr Bahar Shakerian, Dr Mehdi Saadat, Dr Forozan Ganji, Dr Fatemeh Lalehgani and Jafar Shoushtaripour for their kindly help in the laboratory management of sera. 


\section{References}

1. Litman N, Stephen GB. Mumps virus. In: Mandell GL, Bennet JE, Dolin R, eds. Principles and practice of infectious disease, 6th ed. Philadelphia, Elsevier Churchill Livingstone, 2005:Chapter 2.

2. Tischer A, Gerike E. Immune response after primary and re-vaccination with different combined vaccines against measles, mumps, rubella. Vaccine, 2000, 18(14):1382-92.

3. Aksit S et al. Mumps seroprevalence in an unvaccinated population in Izmir, Turkey. Acta paediatrica, 2000, 89(3):370-1.

4. Rasoli M et al. The prevalence of antibody against mumps in 6-15 year children in Shiraz. In: Abstract book of the 12th Iranian Congress of Infectious and Tropical Diseases. Tehran, Islamic Republic of Iran, 17-21 June 2004:36-7.

5. Vajegani M, Bahami F. Seroepidemiology of mumps in children aged 5-10 years old in Tehran [doctoral thesis]. Tehran, Faculty of Medicine, Tehran University of Medical Sciences, 1994.

6. Nigro G, Nanni F, Midulla M. Determination of vaccine-induced and naturally acquired class-specific mumps antibodies by two indirect enzyme-linked immunosorbent assays. Journal of virological methods, 1986, 13(2):91-106.

7. Van den Hof $S$ et al. Antibodies against mumps in The Netherlands as assessed by indirect ELISA and virus neutralization assay. Epidemiology and infection, 2003, 131(1):703-9.

8. Kanbur NO, Derman O, Kutluk T. Agespecific mumps seroprevalence of an unvaccinated population of adolescents in Ankara, Turkey. Japanese journal of infectious diseases, 2003, 56(5-6):213-5.

9. Morgan-Capner P et al. Surveillance of antibody to measles, mumps, and rubella by age. British medical journal, 1988, 297:770-2.

10. Popow-Kraupp T, Kunz C, Hofmann H. Antibody response after application of a new live attenuated mumps vaccine (Pariorix) measured by enzyme-linked immunosorbent assay (ELISA). Journal of medical virology, 1982, 10(2):119-29.

11. Glikmann G, Petersen I, Mordhorst $\mathrm{CH}$. Prevalence of IgG-antibodies to mumps and measles virus in non-vaccinated children. Danish medical bulletin, 1988, 35(2):185-7.

12. Batayneh N, Bdour S. Mumps: immune status of adults and epidemiology as a necessary background for choice of vaccination strategy in Jordan. Acta pathologica, microbiologica et immunologica scandinavica, 2002, 110(7-8):528-34.

13. Chakravarti $A$ et al. Evaluation of serological status of rubella and mumps in children below five years. Indian journal of medical research, 1999, 110:1-3.

14. Nicoara $C$ et al. Decay of passively acquired maternal antibodies against measles, mumps, and rubella viruses. Clinical and diagnostic laboratory immunology, 1999, 6(6):868-71.

15. Profeta ML, Ferrante $P$, Mendogni D. Correlazione tra riscontri sierologici e dati anamnestici nell'ambito delle principali malattie virali dell'infanzia [Relation between serologic verification and anamnestic data on the principal virus diseases of infancy]. Bollettino dell'lstituto sieroterapico milanese, 1987, 66(5):367-76.

16. Tashiro $T$ et al. [Vaccination against rubella, measles, chickenpox, and mumps in nursing students]. Kansenshogaku zasshi, 2004, 78(5):398-403 [in Japanese]. 